tion would have been immeasurably retarded. The conditions under which the invention of patentable inventions is stimulated do not necessitate an inventor relinquishing the pursuit of any trade, occupation, or profession in which he may be engaged. $\mathrm{He}$ is under no obligation to satisfy anyone as to the direction his labours may take, and he is free to devote his talents to the work of invention at such times as he may for himself determine. Moreover, forms of judicial procedure are made available for him by which he can defend his claim to be described as "the true and first inventor" of his invention, whether that be disputed by rival inventors, or opposed on false or fraudulent grounds, or be the subject of official objection.

My scheme for the promotion of scientific research forms the subject of an article in NaruRE of January $2 \mathrm{r}$. The principles of the scheme, which are generally indicated in the article, admit of substantial grants being made out of public monies for discoveries prescribed by Parliament under conditions analogous to those upon which patents for inventions may be obtained, and these conditions would, it is submitted, enlist in research directed to the making of these discoveries many minds possessing the capacity and true genius for this work, which existing methods wholly fail to attract. Allocations of grants may be made, on the conditions specified in the scheme, to discoveries which advance our knowledge of physical and chemical phenomena, and in relation to the more deadly and prevalent of the diseases which afflict humanity.

Allusion is made in the report of the executive committee of the British Science Guild, of which extracts are given in Nature of January 28 , to the Duke of Devonshire's Commission, which was appointed about thirty-eight years ago to inquire into the means available for extending scientific knowledge and advancing scientific progress. We stand to-day, so far as the provision by the State of pecuniary incentives to scientific research is concerned, much in the same position as we did at the conclusion of the prolonged labours of that commission. Since that time the practical applications of physical, chemical, and medical discoveries, not of a patentable nature, and for which no rewards can under existing conditions be obtained, have greatly contributed to the advancement of commercial and industrial progress and to the national well-being. The discovery of the electric waves used in wireless telegraphy, and of the conductivity of certain substances in the state of powder or filings when these waves impinge upon them, are examples of such discoveries. By means of these two discoveries it was found possible to construct systems of wireless telegraphy. If we confine our attention to the practical applications of these discoveries alone, we must perceive that, in addition to the more general beneficent purposes that have been thereby already attained, they have been the means of greatly increasing the effectiveness of our naval power.

In face of facts such as these, it is to be hoped that our legislators will awaken to a recognition of the momentous issues involved in the promotion of research in departments of science which have an intimate connection with public interests. Walter B. Priest.

I Verulam Buildings, Gray's Inn, London, March 3 .

The "Daylight Saving" Bill.

MAY I point out, in addition to the recognised unscientific nature of the proposals of this Bill, that the third Sunday in April for the putting on of the clocks is hardly consistent with the third Sunday in September for putting them back? The length of the day in the third week of April is considerably greater than in the third week of September, and it would be much more consistent if the two equinoctial months March and September were both adopted for the alteration. The fourth Sunday in March, a little after the vernal equinox, has about the same length of day as the third Sunday in September, a little before the autumnal equinox. If it be urged that the temperature of the air in March in this country is too low for summer habits of life, one may reply that it is still too low in April, and even May, despite the long days and high altitude of the sun.

Northwood, March r3. L. C. W. BONACINA. NO. 2055, VOL. 80]
Fireball of February 22.

THE observations of this unusual object are exceedingly numerous, but some of them are discordant, and occasion doubts as to the exact path which the meteor traversed in our atmosphere. The radiant point being inaccurately defined, the direction and height are also to some extent uncertain. Apart from the determination already mentioned in NaTuRE, I have worked out two others, which do not differ very materially except in the elevation at the end. Further descriptions from France of a trustworthy and precise nature will enable the real path over the English Channel to be more certainly ascertained.

\begin{tabular}{|c|c|c|c|c|c|c|}
\hline nt point & $\cdots$ & \multirow{2}{*}{\multicolumn{2}{|c|}{$\begin{aligned}= & 177^{\circ}+13^{\circ} \\
& 50 \text { miles }\end{aligned}$}} & & 190 & $20^{\circ}$ \\
\hline & $\cdots$ & & & $\cdots$ & & \\
\hline$t$ at end & $\cdots$ & 26 & " & $\cdots$ & $4 \mathrm{I}$ & " \\
\hline Len & .. & I 55 & , & $\ldots$ & I 55 & ," \\
\hline el & ra & 2 & ," & $\ldots$ & 25 & ," \\
\hline
\end{tabular}

In the event of the position at $190^{\circ}+20^{\circ}$ being the correct one, the meteor was really a Comæ Berencid, and several fairly good observations from France and the Channel Islands indicate that it is entitled to some degree of confidence.

W. F. Denning.

Bristol, March I4.

\section{Unusual Condition of Nasal Bones in Sphenodon.}

In the osteological collection here there is a skull of Sphenodon with four nasals. In the position of the usual single nasal, right or left, are two bones side by side. As this condition appears to be unusual, it would be interesting to know if any of your readers have come across a similar case. H. W. Unthank. Birkbeck College, Breams Buildings, E.C., March 15.

\section{ENGLISH EARTHWORKS AND THEIR ORIENTATION.'}

THIS work is based upon the recommendations of the Committee on Ancient Earthworks and Fortified Enclosures. Though "written expressly to further the Committee's aims, it has no claim to be an authorised representation of the Committee's views." Pending the completion of the task undertaken by the Committee, this work seems to be the best text-book on the subject. Though the author has "restricted himself to the discussion of earthworks with which he is personally familiar," all classes of earthworks, from the earliest period to the time of the Civil War, are dealt with.

We are too grateful to the author for the well-sifted materials he has supplied to judge the whole work by any defects, especially if those defects concern matters which the author may have considered as lying outside his proper scope of work. But there is one feature of the author's work which calls for special notice. It concerns a line of inquiry which the author has almost altogether left untried, apparently, but which, nevertheless, he submits repeatedly to the test of ridicule. Though he refers respectfully enough to Sir Norman Lockyer's work, he indulges in remarks about the astronomical inquiry which are both unwarranted and inconsiderate, without showing any appreciation of the points in question.

Beyond some vague remarks about the orientation of amphitheatres (p. 589, note), the subject of orientation is almost entirely ignored. Most of the 224 plans published in the book have the cardinal points indicated, without ever a word saying whether the bearings are magnetic or true. The student of orientation must decide the matter for himself as well as he can in each case with the aid of a protractor. Nowhere can he find the slightest con-

1 " Earthwork of England: Prehistoric, Roman, Saxon, Danish, Norman, and Mediæval." By A. Hadrian Allcroft. Illustrated with Plans, Sections, \&c. Pp. xix +7rr. (London: Macmillan and Co., Ltd., r908.) Price $18 s$. net. 
sideration of the wants of the astronomical inquirer, who cannot but treat uncertified plans, so to speak, as so much waste of labour. Unfortunately, one encounters the same difficulty in most works on archæology, so much so that one wonders why any compass lines are drawn on the plans at all. Undated magnetic bearings are useless, and unexplained bearings are, if anything, still more useless.

Our author, however, employs the whole force of his ridicule in belabouring the very class of fellowworkers in the same field he has so wilfully left unprovided for. An observer ventured to say that a curiously symmetrical work on Firle Hill, Sussex, was a "Stonehenge in earth"-Fig. 181 in the book under notice. It was evidently a mistake to take the corners of the central square as of solstitial significance, that is if the bearings of the plan are true. The author, however, seems not to have noticed even that. The observer's main contention are merely the sites of bygone windmills! "(ib.). But elsewhere he notes that "round barrows of large size have been turned to various utilitarian purposes. They were favourite sites for windmills, for example, like the Derry Mount at Nottingham Castle."

A long barrow in Dunstable is called Windmill Hill (p. 53I). That the sites about Lewes are such utilised barrows seems to be highly probable; yet the author winds up his remarks upon a subject he betrays no fitness to discuss with the following peroration:- "The millers of the downs are all but gone, and the last of their mills must soon cease to struggle against the competition of steam roller-mills and the modern taste for tasteless bread; but should there come to their dusty shades any intelligence of the matters which vex the minds of men on earth, they must laugh jollily to think of their old haunts translated into temples of the ' $\operatorname{dim}$ red dawn of man,' of themselves apotheosised into sapient

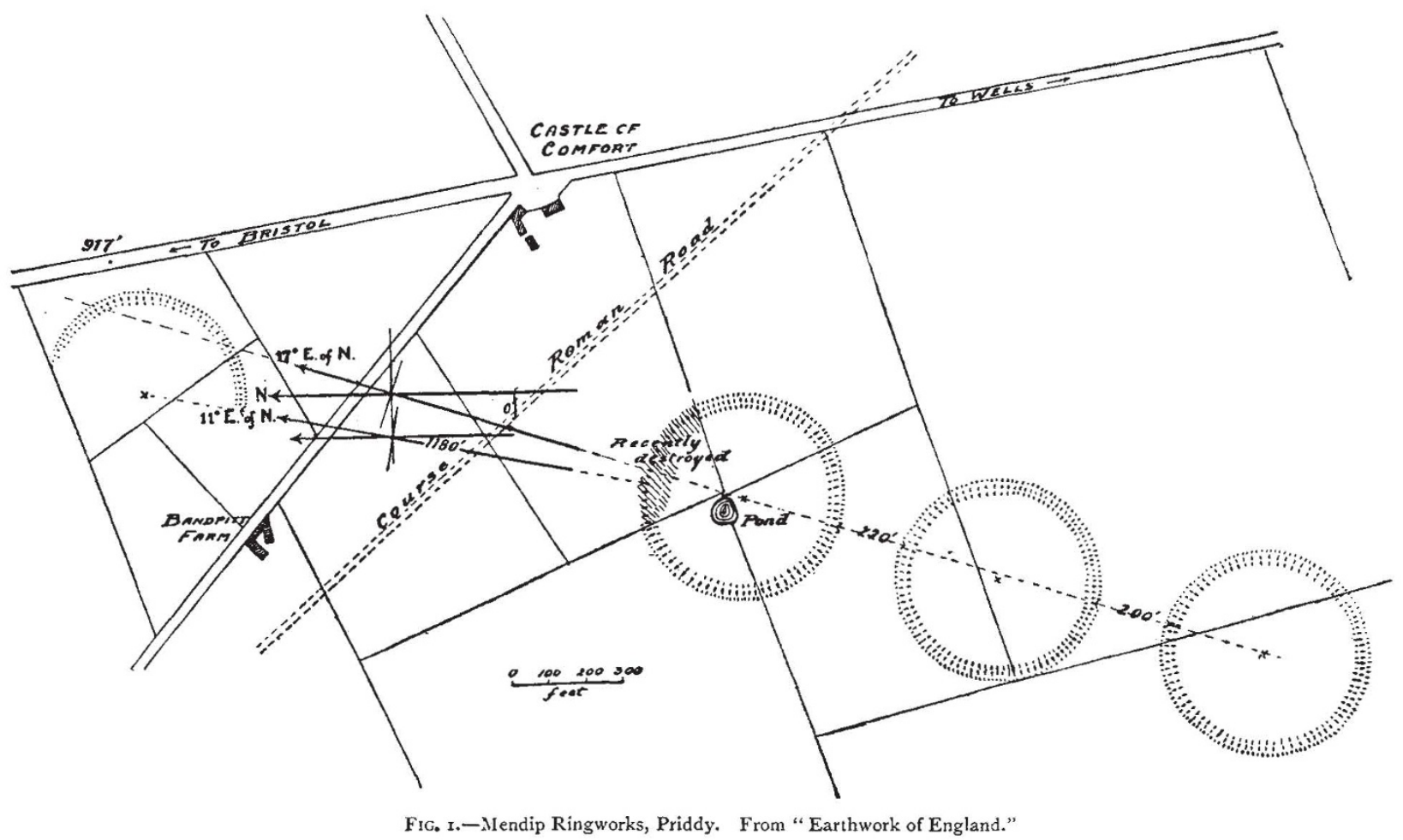

is fully borne out in the plan that a line across the centre of the three works on the spot indicates a May-day orientation. A similar work on Mount Caburn gives a line at right angles to sunrise on May-day (Fig. 180), as well as an equinoctial line. Again, a similar work on Lewes Down (Fig. 182) gives a line at right angles to sunrise at the winter solstice. But instead of submitting such observations to some scientific test, our author indulges in such remarks as the following:-"Whence it is suggested that the whole is a work (Firle Hill) dating from that 'vastly remote epoch' when the year was accounted to begin in May-an epoch when the South Downs were inhabited by an immigrant race who brought with them astronomical ideas once prevalent in Egypt and Chaldea" (p. 537). "A little further investigation would have revealed to both authorities (Pitt-Rivers and the astronomical observer) that there are quite a number of such cryptic works upon the downs about Lewes, and that, in sober fact, they astronomers, and of the later-day Quixotes so overread in Druidical lore that they must needs ride a-tilting against windmills! And where shall the student of earthworks find a more homely lesson in all that an antiquary should be?-cautious, and again cautions, and yet a third time cautious" (p. 539). Where, indeed, shall the student find a more homely lesson on incaution than in the author's remarks on oriented windmill sites? One whom the author may have numbered in his list of "later-day Quixotes so over-read in Druidical lore" (for the author has read the present writer's incursions into that land of mystery) may fairly return the compliment and ask. Who is the real Quixote in the case?

The author can hardly refer to anything so-called "Druidical" in a truly scientific spirit. Dealing formally nowhere with the subject of Druidism, he always refers to it in a prohibitive fashion. It is "an obsession with the multitude" (p. 586). It is something that ridicule has killed (p. 69r). Nothing

NO. 2055, VOL. 80] 
new, we are led to suppose, can be learnt on the subject. We should have liked to know what particularly may be the author's conception of Druidism. It must be rather peculiar to produce the remark on Warne's opinion of the Knowlton ring-works, that they were "sanctuaries of Druidic worship." " Had he written ' astronomical' instead of 'Druidic,' his opinion would have perhaps earned more attention" (p. 566).

Little as the author has done consciously for the student of astronomical archæology (and how much he could have done with little trouble!), we are gratified to find in the plans given scores of orientations agreeing with the theoretical conditions for locality. For instance, the mean azimuth of twenty-two earthworks in and about latitude $5^{\circ}$, which were assumed to be oriented to the summer solstice, ranging from $48^{\circ}$ to $50^{\circ}$, is $48^{\circ} 20^{\prime}$.

The author, like other recent writers who are more or less familiar with the astronomical inquiry in the field of archæology, will have it that the spade is the "solitary instrument" of comparative archæology. It is strange that the writers we have In mind have not tried any astronomical methods. There is something suspicious, as well as unscientific, in this assumption of finality, if not infallibility, for the spade.

With regard to many sites, the spade-work is confessedly disappointing. The author notes that the results of some partial explorations " of the Stripple Stones were as 'negative' as they have been at other spots of the kind " (p. 582). Astronomy, however, supplies us with "positive" information. We find there a definite Capella indication, I250 B.C. ("Stonehenge," p. 293). On the plan given by Mr. Allcroft, we further note definite equinoctial and November alignments.

The series of four circles on the top of the Mendips (see Fig. I) the author is inclined to think is " perhaps of astronomical character" (p. 564). The circles (Fig. I89) bear a striking resemblance in arrangement to the Hurlers in Cornwall ("Stonehenge," pp. 136I40). There are two definite star alignments, either Arcturus at different periods before $\mathrm{r} 300$ B.c., or Capella at later periods, which we hesitate to say. The site is evidently that of a notable observatory. There is a Roman road running at right angles to the line of sunrise at the summer solstice $\left(\mathrm{N} .4 \mathrm{I}^{\circ} \mathrm{W}\right.$. $--N .49^{\circ}$ E.). Another road, N. $6 \mathrm{I}^{\circ}$ E., points to sunrise on May-day. Meeting the last is still another road, az. S. $51^{\circ}$ E., sunrise at the winter solstice.

One excellent result of collating so many plans of earthworks is the establishing of the fact that rectilineal and rectangular camps are by no means exclusively Roman. "The old conviction that all rectangular camps, wherever placed, must necessarily be Roman was completely upset by the excavations of Pitt-Rivers, and is now entirely discredited in England. In Scotland, according to Dr. Christison's view, of a total of more than eighty rectilineal and chiefly rectangular works commonly described as Roman, only seven have furnished any relics to bear out this attribution" (p. 143). The author shows that the "circular plan is the most economical." Why, then, have we straight walls or banks associated with circular works? An examination of the plans discloses the answer. Walls or banks were, of course, erected for defensive purposes, but they were built straight for orientation purposes. More, a straight wall gives the best earthwork orientation. Burrington Camp, Somerset, is a striking illustration in point (see Fig. 2). The only evidence of age the author cites is the finding of flint flakes in some quantity along the edge of the cliff southwards. It is described as " a very curious work, apparently a hybrid between the 'military' and the "ritual 'methods of construction" (p. 582). "Collinson was so perplexed by the oddity of the whole work that he opined it to be 'Druidical,' and to have some unexplained connection with the well-known stone circles at Stanton Drew, eight miles to the northeast" (pp. 583-4).

The plan shows the south bank to be oriented to the equinox. Another bank (B), az. $5^{\circ}$, may be oriented to both sunset at the summer solstice and sunrise at the winter solstice, as there is some height on the north-west. The north-east bank (D), az. N. $\mathrm{I} 7^{\circ}$ E., gives us a familiar datum. Collinson was right, and Burrington and Stanton Drew have the same star alignment, which Sir Norman Lockyer has worked out to be Arcturus, r6go B.c. ("Stonehenge," p. x73). Surely this is another instance where the theodolite has helped the spade, and there

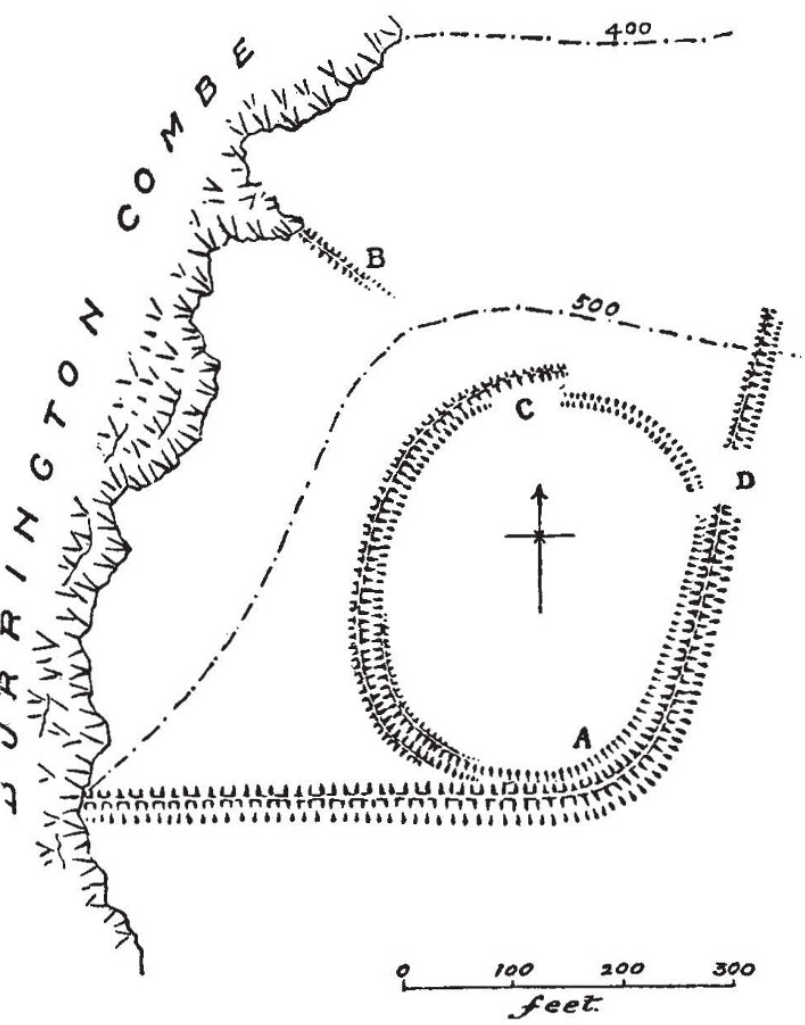

FIG. 2.-Burrington Camp. From " Earthwork of England.

is also something in "Druidism" which has not been reckoned with in Mr. Allcroft's philosophy.

At Arbor Low there seems to be an alignment to Alpha Centauri, the star concerned in our earliest monuments. Here the spade-work also indicates an early period. "The site was explored by $\mathrm{Mr}$. St. George Gray in IgoI-2, whose conclusions were that it was a work of the later Neolithic age, but antedating the Bronze age, that it was not intended as a place of habitation, and that, albeit interments were found within it, it did not appear to have been a place of sepulture at a period closely following its construction" (p. 577). The last sentence is most valuable. Well, an "interment" at the centre of the camp is aligned with a south-east entrance to S. $18^{\circ}$ E., which may be regarded as Alpha Centauri about, say, 2400 B.c. This estimate is based on analogous cases where the same star is concerned.

" Not unlike this (Arbor Low) is Castle Dyke, near 
Aysgarth" (Fig. 195). "At one point in the vallum, on the south-east, a single stone rises slightly above the turf" (pp. 577-8). There is also a gap in the vallum on the south-west, right opposite an entrance on the north-east. Drawing a north-south line between the two southern points mentioned, it is seen that the gap is S. $33^{\circ}$ W., the N.E. entrance N. $33^{\circ}$ E., and the south-west stone S. $33^{\circ}$ E. Taking the north-east outlook into consideration, lat. $54^{\circ}$, dec. $29^{\circ} 30^{\prime}$, we have an indication of Capella about $225^{\circ}$ B.c. But if we take the southeast stone as a direction point--a safe proceeding-we have Alpha Centauri nearly at the same time that we have it at Avebury, which is well within the fourth millennium B.c. At Maiden Castle (S. $34^{\circ}$ E.) we seem to have practically the same datum, and at Muzbury (S. $20^{\circ}$ E.) the same star.

Such are a few instances out of about a hundred or so, which the present writer has noted in this valuable book, of the practical value of uniting the spade and the theodolite in archælogical research. If, as one sincerely hopes, there will be a demand for a second edition, the author will surely remove all cause for the adverse comments made above, in fairness to his fellow-workers. The author has no comfort for those who cannot accept the theory that cromlechs are chambers for the living, and only secondarily tombs for the dead, because of the smallness of some of the chambers. "Primitive man was the best judge of his own requirements, and he may have been quite as comfortable in a 4 -foot pit as in those exiguous 'mound-dwellings' of Wales and the North out of which the 'Celtic imagination' has evolved the theory of a pygmy race" (p. 253). There is surely something Celtic in an author who ascribes the existence of a pygmy race to "Celtic imagination," but that is a minor detail.

The book is replete with very useful notes on placenames. A very doubtful supposition, which he cites, is that which explains "Ambresbury" as derived from emrys, "an enclosure." " The word Emrys early became confused with the name Ambrosius", (p. 128). They are doubtless identical.

In a reference to the present writer's description of the Gorsedd (p. 593), there is a serious mistake. The older plan was not equinoctial, but May-year, the chief point in question.

JOHN GRIFFITH.

\section{DARWIN CELEBRATIONS IN THE UNITED STATES}

THE coincidence of the one hundredth anniversary of the birth of Charles Darwin and the fiftieth anniversary of the publication of "The Origin of Species " in the present year has called forth a series of noteworthy celebrations in the educational and scientific institutions of the United States.

The earliest of these, as recorded already in Nature, was that held in Baltimore on January $I$ by the American Association for the Advancement of Science, which devoted an entire day to the honour of Darwin. A year's preparation had been given to the arrangements for this day, which included a series of ten addresses by the most eminent biologists in the country, who attempted to cover the important fields of Darwin's work, except in geology, which was briefly alluded to in the introductory address by Prof. T. C. Chamberlin, of the University of Chicago, as president of the American Association. Prof. E: B. Poulton was invited from Oxford as the special representative of the English universities, and as the leading exponent of pure Darwinism. His important opening address, entitled "Fifty Years of Darwinism," will be used as an introduction to a volume, now in the press, to be published by Messrs. Henry Holt and Co., New York, which will include all the addresses of this important series. Each of these addresses was partly retrospective and partly related to the progress in the special field of the speaker since the time of Darwin.

A series of tributes to the great naturalist was arranged for his birthday, February 12, in colleges, universities, and various scientific institutions in all parts of the United States. The present writer has especially in mind addresses at Columbia University, Cornell University, University of Chicago, University of Illinois, North-Western University (Evanston, I1l.), University of Missouri, and University of Syracuse.

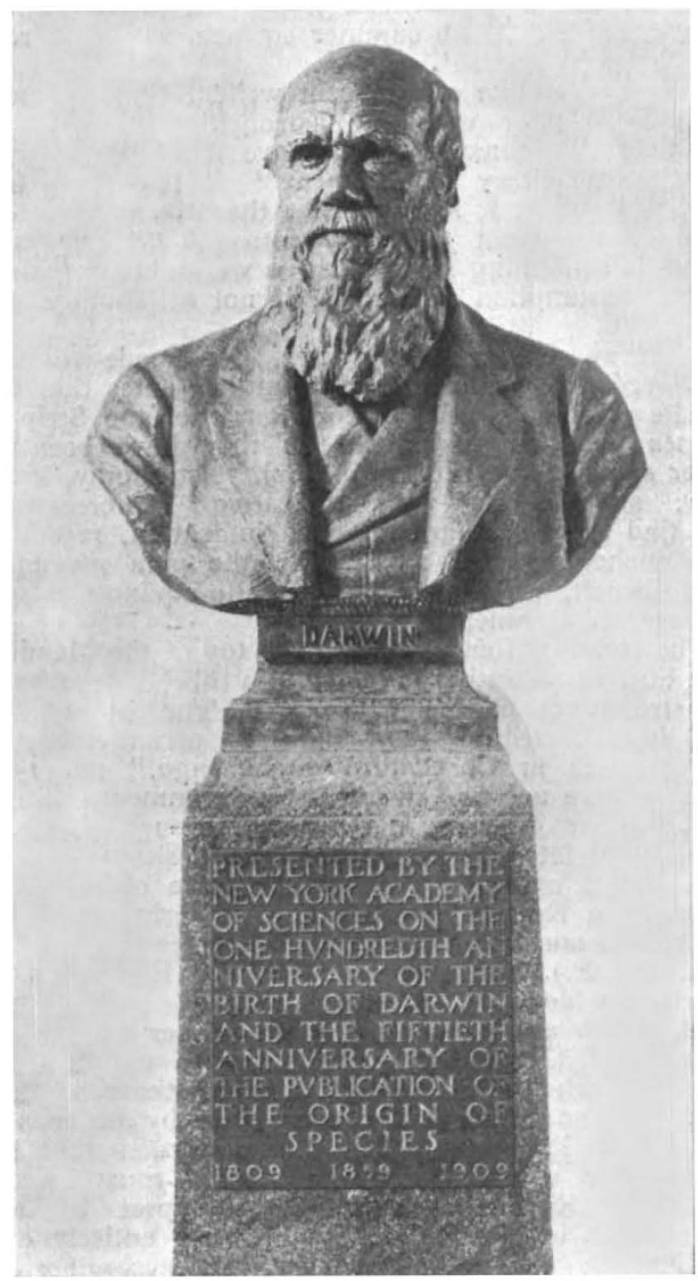

Other celebrations arranged were those of the Academy of Natural Sciences of Philadelphia on February 16 , at which the principal address was made by Prof. E. G. Conklin (now of Princeton University). The coincidence of Darwin's birth with that of Abraham Lincoln suggested in many of the speeches and addresses several striking parallels in the personal character of these two great men: their simplicity, unconsciousness of power, abhorrence of slavery, clearness of expression, singleness of purpose. Repeatedly in Press and pulpit utterances Darwin was referred to as the emancipator of human thought, Lincoln as the emancipator of the negro race. The attitude of the pulpit and clergy everywhere has 